\title{
Anterosuperior rehabilitation with metal-free fixed prosthesis based on zirconia
}

\author{
Sthelen Nayara Cenci ${ }^{1}$, Igor Alessandro Gontarsky ${ }^{1}$, Marcella Goetz Moro ${ }^{2}$, \\ Lidia Olga Bach Pinheiro ${ }^{1}$, Adriana Postiglione Bührer Samra ${ }^{1}$
}

Correspondence: Dr. Adriana Postiglione Bührer Samra

Email: adrianasamra@bol.com.br

\author{
'Department of Dentistry, State University of Ponta \\ Grossa (UEPG), Paraná, Brazil, \\ 2Department of Stomatology, Discipline of \\ Periodontology, School of Dentistry, University of São \\ Paulo (FOUSP), São Paulo, Brazil
}

\section{ABSTRACT}

The loss of upper front dental elements causes functional and psychosocial problems to the affected individuals. In this case report, the treatment planning considered hard and soft tissue loss for a complex fixed partial denture (FPD) rehabilitation. The six-element, all-ceramic FPD was manufactured using a computer-aided design/computer-aided manufacturing system with zirconia framework, veneered with leucite-reinforced ceramic. Ceramic artificial gum was also produced to guarantee tooth-facial proportions as well as lip support, promoting both esthetics and phonetics. The material's mechanical properties allowed for the coupling of the esthetic and mechanical requirements, proving an alternative to the well-established metal-ceramic technology, optimizing biomimetic. One of the endodontic-treated abutment teeth required a radicular retainer with cast metal post, but because of the opacity of zirconia, the esthetics of the prosthesis was not compromised. The low silica content of high resistance ceramics such as zirconia hampers the adhesive cementation, with numerous studies advocating for different cementation protocols, with no clear scientific consensus so far. In the present case, the internal surface of the FPD was initially blasted with aluminum oxide, followed by the application of a universal adhesive system containing 10-methacryloyloxydecyl dihydrogen phosphate. Finally, cementation to the dental structure was conducted with dual-cure self-adhesive resin cement.

Key words: Computer-aided design, dental, denture, esthetics, fixed, partial

\section{INTRODUCTION}

In the search for esthetics materials that are mechanically similar to metal, the high resistance ceramics are an alternative to the metal ceramics. ${ }^{[1,2]}$ The yttrium oxide partially stabilized tetragonal zirconia (Y-TZP) stands out for meeting such requirements ${ }^{[1-3]}$ thanks to a computer-aided design/computer-aided manufacturing (CAD/CAM) system, which enabled the milling of all-ceramic extensive dental prostheses. ${ }^{[1,4]}$

\begin{tabular}{|l|l|}
\hline \multicolumn{2}{|c|}{ Access this article online } \\
\hline Quick Response Code: \\
\hline
\end{tabular}

\section{CASE REPORT}

A 46-year-old female patient wished to replace her removable denture for a fixed one, refusing dental implants and removable denture [Figure 1]. She displayed an open bite with the absence of both central and left lateral upper incisors, including substantial loss of the corresponding soft tissue [Figure 2]. The oral environment was adjusted before the rehabilitation.

This is an open access article distributed under the terms of the Creative Commons Attribution-NonCommercial-ShareAlike 3.0 License, which allows others to remix, tweak, and build upon the work non-commercially, as long as the author is credited and the new creations are licensed under the identical terms.

For reprints contact: reprints@medknow.com

How to cite this article: Cenci SN, Gontarsky IA, Moro MG, Pinheiro LO Samra AP. Anterosuperior rehabilitation with metal-free fixed prosthesis based on zirconia. Eur J Dent 2017;11:253-7.

DOI: 10.4103/ejd.ejd_57_17 
Thereafter, a six-element fixed partial denture (FPD) was proposed, whereby the remaining upper front teeth would be used for abutment, with dental element 13 receiving an intraradicular retainer [Figure 3]. By esthetic requirements, the planning was made digitally following the digital smile design principles, and the chosen materials were to be all ceramic.

Occlusal stability led to the planning of an FDP keeping the central occlusion pattern. Ceramic artificial gum was associated with the white esthetics concept in an attempt to minimize open bite and tissue loss. Color A2 was chosen for the dental elements, while photographs were used to select the ceramic gum.

The lateral incisor and right canine teeth presented pulp vitality and adequate bone support, while the left canine, endodontically treated, requiring a cast metal post. One week after postcementation, the three abutments were prepared by high-speed diamond-coated milling with reductions of approximately $1.5 \mathrm{~mm}$ (axial), and $2.0 \mathrm{~mm}$ (occlusal), with finish line in rounded shoulder with $1.0 \mathrm{~mm}$ wide. Sequentially, the impression was made by the double-cord technique using putty and light body addition polyvinyl siloxane. Adjustment and

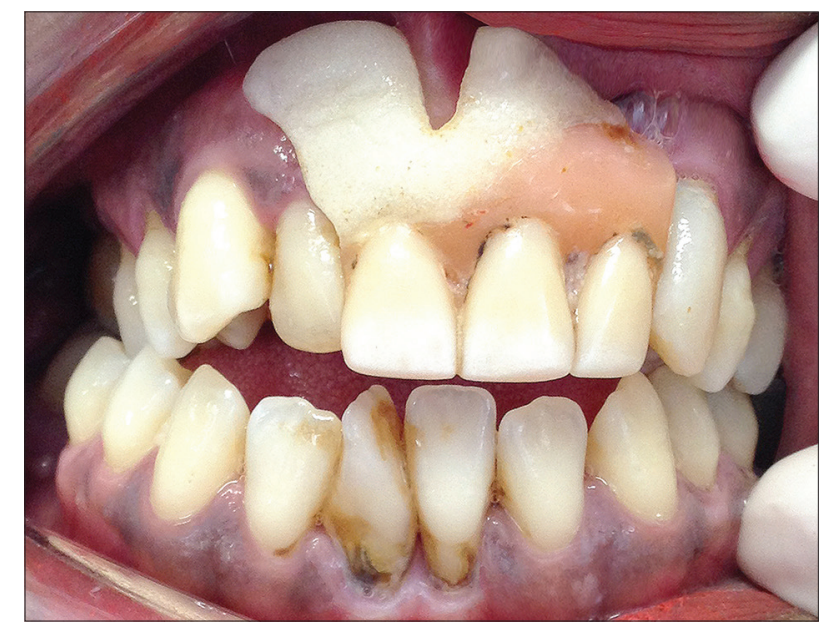

Figure 1: Initial photo with provisional prosthesis unsatisfactory

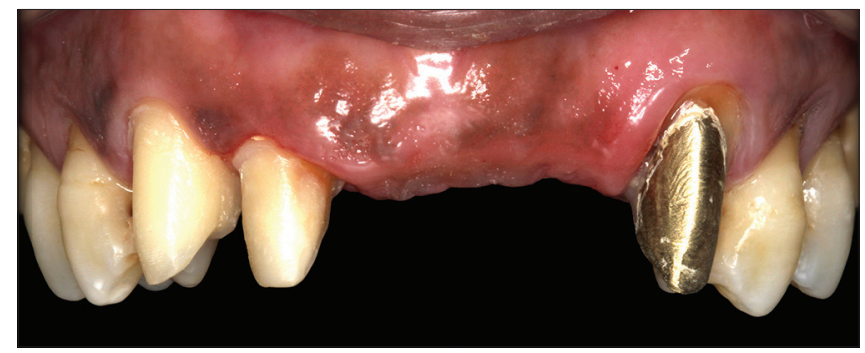

Figure 3: Abutments were prepared by high-speed diamond-coated (KG Sorensen ${ }^{\circledR}$, São Paulo, Brazil) temporary cementation were done [Figure 4]. The cast model was scanned by the CAD/CAM system, followed by digital planning and milling of the infrastructure from a single presintered block of high translucency [Figure 5].

The framework was veneered with leucite-reinforced feldspar ceramic in the dental elements, and Ceramax in the artificial gum. FPD underwent blasting with aluminum oxide and chemical treatment with a single layer of silane for $60^{\prime \prime}$, followed by adhesive and photoactivation for $40^{\prime \prime}$. Dental prophylaxis with pumice stone preceded usage of the self-adhesive resin cement. After removal of the cement excesses, each abutment was photopolymerized for 60 " / face [Figures 6-8]. Oral hygiene orientations were reinforced at the end of cementation.

\section{DISCUSSION}

Digital planning revealed the necessity of replacement of the lost soft tissue for display of the gum through the high smile line. ${ }^{[5]}$ Initially, several attempts of longer provisional crowns were made to compensate soft tissue loss, but they turned out esthetically unsatisfying. Finally, fixed dentogingival prosthesis with ceramic artificial gum was proven to be the best choice. ${ }^{[6]}$

The endodontic-treated abutment needed a cast metal post due to the limited coronal remnants, beside the

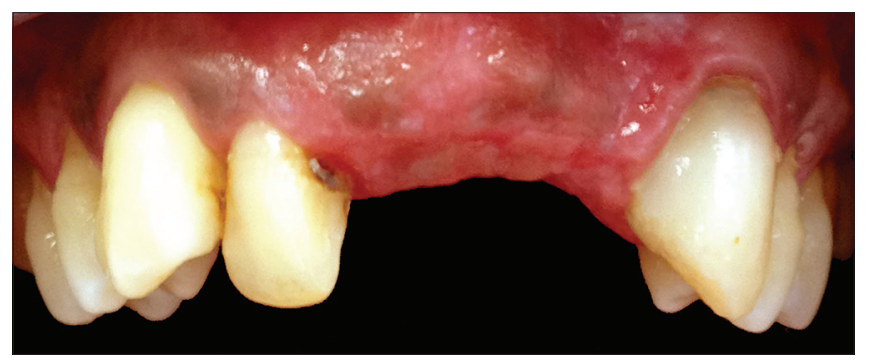

Figure 2: Loss of upper front dental elements

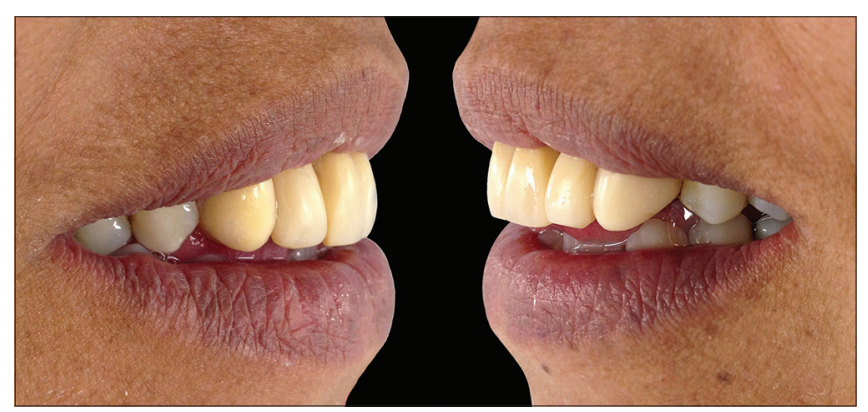

Figure 4: Right and left lateral view during the provisional prosthesis phase 


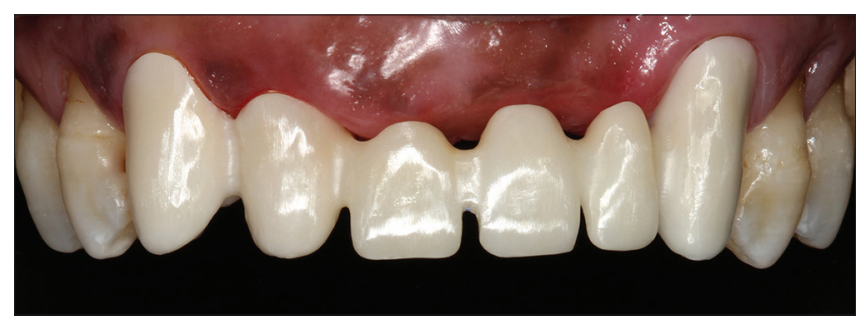

Figure 5: Zirconia infrastructure test (Y-TZP-Zirkonzahn ${ }^{\circledast}$, Bruneck, Itália)
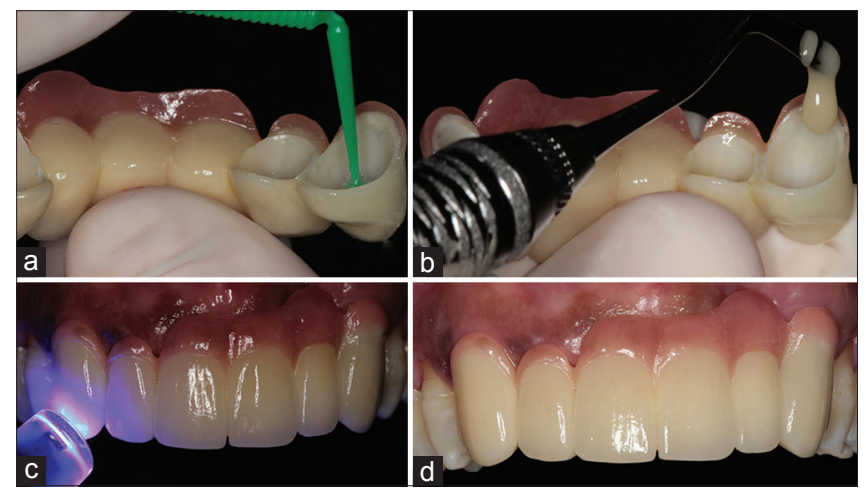

Figure 7: (a) Silane (Monobond S, Ivoclar Vivadent) chemical activation for $60 \mathrm{~s}$, followed by single layer of adhesive (Scotchbond ${ }^{\mathrm{TM}}$ Universal Adhesive, 3M). (b) Insertion of dual auto adhesive resin cement (RelyX $\left.{ }^{\mathrm{TM}} \mathrm{U} 200,3 \mathrm{M} \mathrm{ESPE}^{\circledR}\right)$. (c) dental positioning and fixed partial denture were photopolymerized (Optilight LD MAX, Gnatus ${ }^{\circledR}$, São Paulo, BR) for $60 \mathrm{~s}$ face in each abutment. (d) cemented prosthesis

abutment function. ${ }^{[7]}$ The structural opacity of the FPD concealed the metallic aspect, maintaining esthetics. ${ }^{[8]}$

The Y-TZP gained space in dentistry for combining resistance to esthetics, ${ }^{[8]}$ unlike the metal. ${ }^{[1,3]}$ The improvement of this ceramic guarantees flexural strength and high tenacity due to its crystalline composition, increasing its indications, ${ }^{[1]}$ although limiting their optical properties of translucency and hence being employed as a core to be veneered with glass ceramics. ${ }^{[8]}$ All ceramic FPDs are consensus in dental practice and seem to be a worldwide trend, yet, they have to be well understood to optimize its characteristics and physical properties. ${ }^{[1]}$

Although zirconia resistance is questioned in high masticatory forces areas, it can be considered the most suitable substructure ceramic in rehabilitation for anterior-free contact teeth. ${ }^{[9,10]}$ Other two studies ${ }^{[2,11]}$ that followed patients which use prostheses, totalizing 27 (from up to 6 units), and thirty prostheses all exclusively ceramic, for 7 and 5 years, 0 and 2 structural failures occurred, respectively. . The occurring failures were posterior, with the first in the region of the connector, supposing that the location of the prostheses is determinative to longevity, corroborating

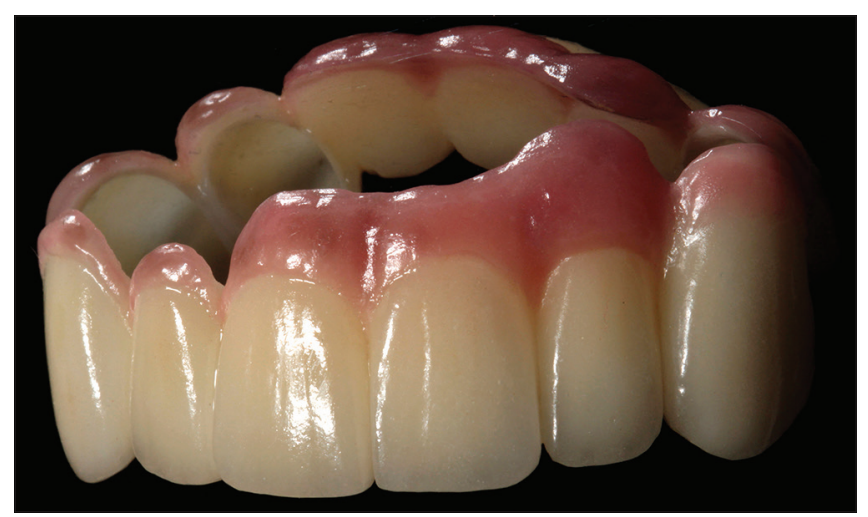

Figure 6: Fixed partial denture finished. Stratification with feldspathic ceramics based on leucite (IPS Empress E-Max ${ }^{\circledast}$, Ivoclar Vivadent, São Paulo, Brazil) and Gingival ceramics (Ceramax, Talmax ${ }^{\circledR}$, Curitiba, Brazil)

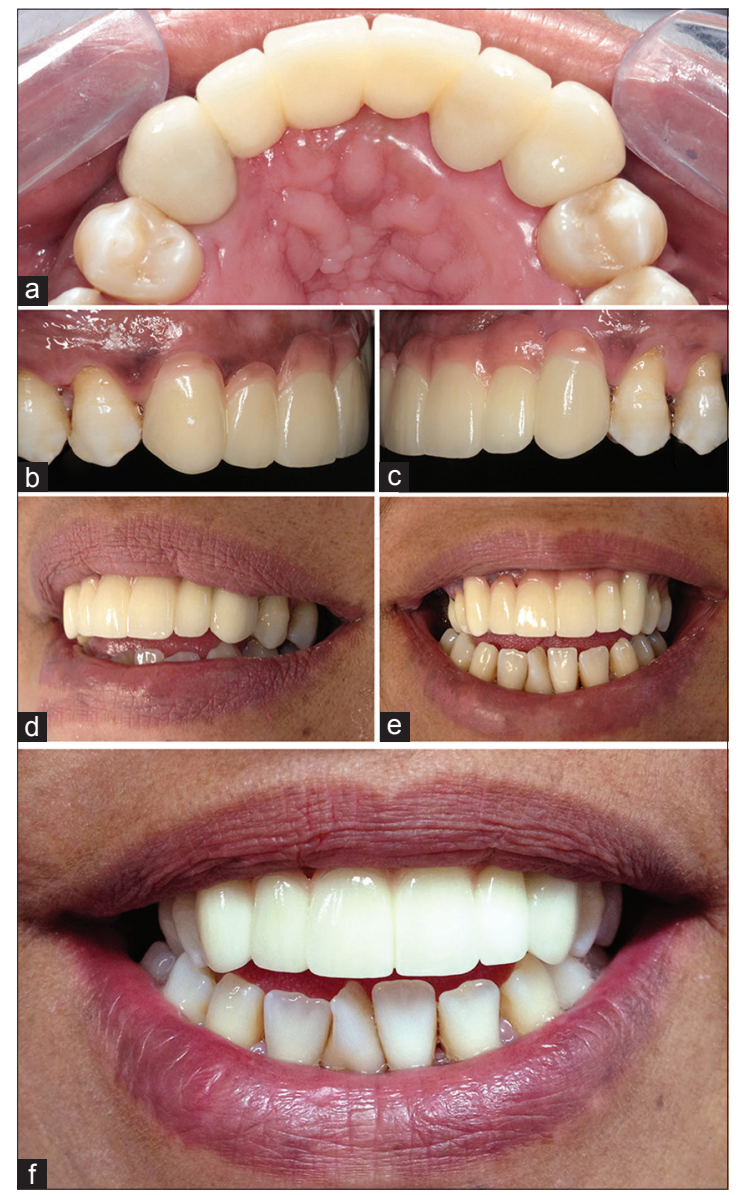

Figure 8: Prosthesis installed. (a) by occlusal view; (b and c) by right and left lateral view. (d-f) front view

with the results found in studies, where zirconia has its limited use on molar and posterior teeth due to loads of mastication present in the region. ${ }^{[9,11]}$ The connectors exhibit limited design and dimensions, increasing the susceptibility to concentrate tension and risk of fractures. ${ }^{[1]}$ A consensus about the ideal dimension for each material is undefined because 
it involves variables such as available space, the posterior region being more critical than the anterior hereby rehabilitated. In the present clinical case, there were two abutments close to each other, making its design even more challenging. However, the software used for virtual design ensured dimensions of all components with adequate resistance, ${ }^{[1]}$ only allowing milling with requirements within its own predefined patterns. This data confer the prosthesis with favorable longevity characteristics.

The CAD/CAM system has expanded the indications of fixed ceramic prosthesis and improved their adaptation, guaranteeing increased internal and marginal adaptation. ${ }^{[1,4]}$ However, Y-TZP, commercialized in blocks, is machined in mono block, requiring adequate preparation of the three abutments with reductions as referenced according to biomechanical principles that guaranteed a coinciding insertion axis, retention, and structural rigidity simultaneously. ${ }^{[12]}$ The cervical preparation is responsible for the adaptation and marginal integrity and consequently, for the longevity of the system. Therefore, the finishing in rounded shoulder ${ }^{[1]}$ propitiated the precise adaptation and constant ceramic thickness, favoring load distribution and stress resistance while minimizing the tensions and consequently preventing cohesive fractures. ${ }^{[12]}$ Yet to be considered, even long-extension bridges are milled in one piece, which might lead to strain development, especially in angled-type bridges. Hence, they must present passive fit, since soldering, as is performed in metal ceramics, cannot be done here. ${ }^{[13]}$ Another concern is with regard to the veneering technique, which may also lead to strain development. In spite of the precision of the framework, the application of ceramic veneering results in an increase in strain development. ${ }^{[14]}$ Chipping of the veneering ceramic is frequently associated with the failure of all-ceramic prostheses. As evidenced in several clinical follow-up studies, ${ }^{[1,2,9,12]}$ this failure generates uncertainties as to the longevity of these prostheses and is associated with factors such as modulus of structural elasticity, different coefficients of thermal expansion of the ceramics, application technique and firing, inappropriate thickness, and occlusal overload. ${ }^{[2]}$ In the present clinical case, the FPD followed the mechanical principles required by the materials.

The low silica content of Y-TZP jeopardizes the conventional adhesive technique. ${ }^{[1]}$ Blasting is recommended to increase surface roughness and assure micromechanical retention, including the association of primers and/or adhesives. ${ }^{[1,8]}$ After aluminum oxide blasting, FPD was subjected to a silane coupling agent. ${ }^{[2]}$ Although silanization to zirconia is uncertain, it is done on the assumption of increased surface energy and wettability, when made associated with sandblast, ${ }^{[15]}$ favoring the action of cement. ${ }^{[1,8]}$ The universal adhesive in use disposed the methacryloyloxydecyl dihydrogen phosphate monomer ${ }^{[1]}$ that structurally interacts with the surface oxides of zirconia ${ }^{[1,8]}$ and with the methacrylate matrix of the resin cement seems uniting them chemically. ${ }^{[8]}$ The self-etching cement guaranteed union to the dental structure even without previous treatment, while its monomeric composition also seems to react to the available oxides, promoting some chemical adhesion additional to the mechanical interlocks. ${ }^{[16]}$ Despite aforementioned related, long-term stability of the adhesion is a concern yet. ${ }^{[15]}$

One year after the cementation, FPD was checked, stable, with no modifications, and the patient related to be pleased and comfortable with the rehabilitation.

\section{CONCLUSION}

Although all-ceramic FPDs are extensively used in clinical practice, dentists have to consider several aspects of the material to overcome its limitations, as though as to take benefit of its advantages. All ceramic rehabilitations are world widespread, with improvements been launched frequently, demanding more studies to confirm them evidence based to allow clinical use.

\section{Financial support and sponsorship Nil.}

\section{Conflicts of interest}

There are no conflicts of interest.

\section{REFERENCES}

1. Komine F, Blatz MB, Matsumura H. Current status of zirconia-based fixed restorations. J Oral Sci 2010;52:531-9.

2. Solá-Ruíz MF, Agustin-Panadero R, Fons-Font A, Labaig-Rueda C. A prospective evaluation of zirconia anterior partial fixed dental prostheses: Clinical results after seven years. J Prosthet Dent 2015;113:578-84.

3. Rashid H. The effect of surface roughness on ceramics used in dentistry: A review of literature. Eur J Dent 2014;8:571-9.

4. Rashid H, Sheikh Z, Misbahuddin S, Kazmi MR, Qureshi S, Uddin MZ. Advancements in all-ceramics for dental restorations and their effect on the wear of opposing dentition. Eur J Dent 2016;10:583-8.

5. Arias DM, Trushkowsky RD, Brea LM, David SB. Treatment of the patient with Gummy smile in conjunction with digital smile approach. Dent Clin North Am 2015;59:703-16.

6. Barzilay I, Irene T. Gingival prostheses - A review. J Can Dent Assoc 2003;69:74-8.

7. Faria AC, Rodrigues RC, de Almeida Antunes RP, de Mattos Mda G, 
Ribeiro RF. Endodontically treated teeth: Characteristics and considerations to restore them. J Prosthodont Res 2011;55:69-74.

8. Seabra B, Arantes-Oliveira S, Portugal J. Influence of multimode universal adhesives and zirconia primer application techniques on zirconia repair. J Prosthet Dent 2014;112:182-7.

9. Bramanti E, Cervino G, Lauritano F, Fiorillo L, D'Amico C, Sambataro S, et al. FEM and Von Mises analysis on prosthetic crowns structural elements: Evaluation of different applied materials. ScientificWorldJournal 2017;2017:1029574.

10. Lauritano F, Runci M, Cervino G, Fiorillo L, Bramanti E, Cicciù M. Three-dimensional evaluation of different prosthesis retention systems using finite element analysis and the Von Mises stress test. Minerva Stomatol 2016;65:353-67.

11. Schmitter M, Mussotter K, Rammelsberg P, Gabbert O, Ohlmann B. Clinical performance of long-span zirconia frameworks for fixed dental prostheses: 5-year results. J Oral Rehabil 2012;39:552-7.
12. Goodacre CJ, Campagni WV, Aquilino SA. Tooth preparations for complete crowns: An art form based on scientific principles. J Prosthet Dent 2001;85:363-76.

13. Miyazaki T, Hotta Y. CAD/CAM systems available for the fabrication of crown and bridge restorations. Aust Dent J 2011;56 Suppl 1:97-106.

14. Karl M, Graef F, Wichmann M, Krafft T. Passivity of fit of CAD/CAM and copy-milled frameworks, veneered frameworks, and anatomically contoured, zirconia ceramic, implant-supported fixed prostheses. J Prosthet Dent 2012;107:232-8.

15. Mahmoodi N, Hooshmand T, Heidari S, Khoshro K. Effect of sandblasting, silica coating, and laser treatment on the microtensile bond strength of a dental zirconia ceramic to resin cements. Lasers Med Sci 2016;31:205-11.

16. Hattar S, Hatamleh M, Khraisat A, Al-Rabab'ah M. Shear bond strength of self-adhesive resin cements to base metal alloy. J Prosthet Dent 2014;111:411-5. 